\title{
Potencial alelopático de extratos aquosos de Melissa officinalis L. e Mentha x villosa L. na germinação e vigor de sementes de Plantago major $L$..
}

\author{
BONFIM, F.P.G. ${ }^{* 1}$; HONÓRIO, I.C.G. ${ }^{1}$; CASALI, V.W.D. ${ }^{1}$; FONSECA, M.C.M ${ }^{2}$; MANTOVANI-ALVARENGA, E. ${ }^{1}$; \\ ANDRADE, F.M.C.' PEREIRA, A.J.'; GONÇALVES, M.G'. \\ ${ }^{1}$ Universidade Federal de Viçosa-UFV, Departamento de Fitotecnia. Av. Ph Rolfs, s/n, Centro, 36570-000, Viçosa \\ MG. ${ }^{2}$ EPAMIG, Unidade Regional Zona da Mata, Campus UFV, n466 Vila Gianetti. CEP: 36571-000. Viçosa-MG. \\ filipegiardini@yahoo.com.br
}

\begin{abstract}
RESUMO: O objetivo do trabalho foi avaliar o efeito dos extratos aquosos de hortelã e melissa na germinação e vigor de sementes de tanchagem. O experimento foi conduzido no Departamento de Fitotecnia da Universidade Federal de Viçosa, no mês de abril de 2011. O delineamento utilizado foi o inteiramente casualizado com cinco tratamentos (testemunha, 25\%, 50\%, $75 \%$ e $100 \%$ do extrato aquoso de hortelã e melissa) e quatro repetições. Os extratos foram preparados utilizando a parte aérea das plantas, na proporção de $100 \mathrm{~g}$ de planta para $1 \mathrm{~L}$ de água destilada. Foram utilizadas 50 sementes de tanchagem em cada caixa gerbox, previamente umedecido com os extratos aquosos (correspondentes aos tratamentos), estas foram levadas para germinar em câmara de germinação, em temperatura de $20^{\circ} \mathrm{C}$, fotoperíodo de 16 horas luz e 8 horas escuro, por 14 dias. Durante esse tempo foram feitas às contagens diárias das sementes germinadas para calcular o índice de velocidade de germinação e ao final dos 14 dias foi calculada a porcentagem de germinação. Sementes de tanchagem não submetidas aos extratos aquosos de melissa e hortelã apresentaram-se mais vigorosas quando comparado com as concentrações, evidenciando o potencial alelopático de melissa e hortelã sobre a sua qualidade fisiológica.
\end{abstract}

Palavras-chave: tanchagem, hortelã, melissa e alelopatia.

ABSTRACT: Allelopathic effect of extracts of Melissa officinallis L. and Menthax villosa L. on seed germination and vigor of Plantago major $L$. The aim of this work was to evaluate the effect of aqueous extracts of Melissa officinallis and Mentha $x$ villosa for the germination and vigor of Plantago major seeds. The experiment was conducted at the Plant Science Department, Federal University of Viçosa, in April 2011. The design was a completely randomized design with five treatments (control, $25 \%, 50 \%, 75 \%$ and $100 \%$ of the aqueous extract of Mentha $x$ villosa and Melissa Officinallis) and four replications. The extracts were prepared utulizando the shoots of plants at the rate of $100 \mathrm{~g}$ of plant to $1 \mathrm{~L}$ of distilled water. We used 50 Plantago major seeds in each box incubator and these were subsequently placed in a germination chamber. 14 days during the counting of germinated seeds per day to calculate the index of germination speed and the end of 14 days was the germination percentage. Plantago major seeds not subjected to aqueous extracts of lemon balm and mint showed higher values in the variables studied when compared to other concentrations, showing the allelopathic potencial of Melissa officinallis and Mentha $x$ villosa on the development of plantain, determined by germinating.

Key words: plantain, mint, lemon balm, allelopathy.

\section{INTRODUÇÂO}

A alelopatia pode ser definida como o processo pelo qual produtos do metabolismo secundário de vegetais são liberados, impedindo a germinação e o desenvolvimento de outras plantas relativamente próximas (Soares, 2000) ou que são cultivadas em solo que antes foram plantadas espécies que liberaram esses metabólitos, que interferem na divisão celular, na permeabilidade das membranas, na ativação de enzimas e na produção de hormônios pela planta (Rodrigues et al., 1992).

Recebido para publicação: agosto de 2011

Aceito para publicação: dezembro de 2011

Rev. Bras. PI. Med., Botucatu, v.13, especial, p.564-568, 2011. 
A hortelã (Mentha $x$ villosa L.) é originária da Europa, pertencente à família Labiatae, também conhecida como hortelã-comum, hortelã-de-tempero, hortelã rasteira, mentrasto, etc. É carminativa, antiespasmódica, estomáquica, expectorante, antiséptica, colerética, colagoga e vermífuga (Martins et al., 2002). A melissa (Melissa officinalis L.), conhecida como erva-cidreira verdadeira, também possui outros nomes populares como chá-de-França, cidrilha, citronelamenor, erva-luísa, e melissa romana. Pertence à família Lamiaceae, de origem Asiática e Européia, é cultivada no Brasil a mais de um século (Correa Júnior et al., 1994). Ambas possuem grande interesse da indústria farmacêutica devido à sua atividade antioxidativa, antimicótica, sedativa e antivirótica (Lorenzi \& Matos, 2002).

A Plantago major conhecida como tanchagem, tansagem ou língua de vaca, é originária do continente europeu e foi introduzida em diversas regiões do mundo, podendo ser encontrada em vários países da África, da Ásia e das Américas. No Brasil a espécie foi encontrada espontaneamente, principalmente em áreas sob clima temperado, em associações com outras plantas (Bacchi et al., 1984). A parte mais utilizada da espécie são as folhas que contém princípios ativos como flavonóides, taninos, mucilagens e saponinas, além de serem ricas em ácidos orgânicos, sais de potássio e vitamina C (Jorge \& Markman, 1994; Kawaslity et al., 1994). São comumente utilizadas como expectorantes, antidiarréicas, cicatrizantes, adstringentes, emolientes, depurativas do sangue; além de utilizadas em inflamações bucofaríngeas, dérmicas, gastrintestinais e das vias urinárias. Em gargarejos a tanchagem é usada contra inflamações da garganta, anginas e gengivas sangrentas (Lorenzi, 2002).

Experimentos em laboratório vêm sendo desenvolvidos com a finalidade de avaliar, sob condições ótimas de temperatura e umidade, os efeitos dos extratos aquosos, da parte aérea e raízes de plantas, na germinação de sementes de diversas espécies (Pires et al., 2001). Estudos sobre efeito alelopático entre plantas tornam-se de extrema importância, uma vez que a utilização destas espécies pode contribuir na determinação de manejos adequados, sugerindo espécies apropriadas ao consórcio. O consórcio é alternativa viável no cultivo de plantas medicinais, no entanto, vegetais superiores ou inferiores podem produzir substâncias químicas, com ação direta ou indireta, estimuladora ou inibidora, que influencia o desenvolvimento da comunidade de plantas, devido às substâncias químicas liberadas no ambiente (Rice, 1984). Sendo assim, o presente trabalho teve como objetivo avaliar o efeito dos extratos aquosos de hortelã e melissa na germinação e vigor de sementes de tanchagem.

\section{MATERIAL E MÉTODO}

O experimento foi conduzido no Laboratório de Melhoramento de Hortaliças do Departamento de Fitotecnia, da Universidade Federal de Viçosa, no município de Viçosa, na Zona da Mata Mineira, coordenadas geográficas $42^{\circ} 52^{\prime} \mathrm{W}$ e $42^{\circ} 50^{\prime} \mathrm{W}$ de longitude e $20^{\circ} 44^{\prime} \mathrm{S}$ e $20^{\circ} 47^{\prime} \mathrm{S}$ de latitude, Brasil, no mês de abril de 2011 .

Os extratos aquosos de plantas de hortelã e melissa foram obtidos da parte aérea fresca, a qual foi triturada, em liquidificador, durante cinco minutos, na proporção de $100 \mathrm{~g}$ de folhas frescas em $1 \mathrm{~L}$ de água destilada, conforme Barreiro et al. (2005), sendo o extrato filtrado em filtro de pano, por cinco minutos. O delineamento utilizado foi o inteiramente casualizado, com cinco tratamentos e quatro repetições, cada parcela experimental constituída por 50 sementes. Os tratamentos foram: testemunha (água destilada, caracterizada por concentração de $0 \%$ ) e os extratos aquosos de hortelã e melissa nas concentrações de $25 \%, 50 \%$, $75 \%$ e $100 \%$, adquiridos por meio de diluição em água destilada.

As sementes de tanchagem (Plantago major), adquiridas do banco de germoplasma do Grupo Entre-Folhas, Viçosa, Minas Gerais, Brasil, foram colocadas em câmara de germinação, modelo TE-401 (TECNAL), em caixas gerbox com papel germitest previamente umedecidos com 12 $\mathrm{mL}$ dos extratos (tratamentos), mantidas a $20^{\circ} \mathrm{C}$, fotoperíodo de 16 horas luz e 8 horas escuro, por 14 dias. Os testes de germinação e vigor seguiram recomendações e critérios estabelecidos pelo Ministério da Agricultura (BRASIL, 1992).

As variáveis analisadas foram: Porcentagem de germinação e Índice de velocidade de germinação, essa como um índice de vigor. A porcentagem de germinação foi determinada ao $14^{\circ}$ dia após a semeadura, computando-se o número de plântulas normais, sendo os dados transformados para arcosseno $\sqrt{X / 100}$. A determinação foi dada pelo somatório da razão entre o número de sementes germinadas cada dia sobre o dia da avaliação.

$$
\begin{aligned}
& I V G=G_{1} / N_{1}+G_{2} / N_{2}+G_{3} / N_{3}+\ldots+G_{n} / N_{n} \\
& \text { Onde: } \\
& G_{1}, G_{2}, G_{3}, \ldots, G_{n}=\text { número de sementes }
\end{aligned}
$$
germinadas no dia da observação. semeadura.

$\mathrm{N}_{1}, \mathrm{~N}_{2}, \mathrm{~N}_{3}, \ldots, \mathrm{N}_{\mathrm{n}}=$ número de dias após a

Os resultados foram submetidos à análise de regressão, sendo ajustadas equações aos dados avaliados e os coeficientes testados pelo teste t, no programa SAEG.

Rev. Bras. PI. Med., Botucatu, v.13, especial, p.564-568, 2011. 


\section{RESULTADO E DISCUSSÃO}

Foram observadas diferenças significativas entre as concentrações do extrato aquoso de melissa na variável índice de velocidade de germinação (IVG), não sendo observada na variável porcentagem de germinação (PG). Resultado semelhante foi encontrado por Barreiro et al. (2005), onde verificaram que o extrato aquoso da parte aérea de barbatimão não afetou significativamente a porcentagem de germinação de pepino, nas concentrações utilizadas, fervido ou não.

Diferenças significativas também foram encontradas nas concentrações do extrato aquoso de hortelã em todas as variáveis avaliadas [índice de velocidade de germinação (IVG) e porcentagem de germinação de (PG)] (Tabela 1). Bonfim et al. (2007) indicam que a hortelã apresenta efeito alelopático na germinação de sementes de Lactuca sativa, provavelmente devido os monoterpenos presentes nas espécies do gênero Mentha.

Sementes de tanchagem não submetidas aos extratos aquosos de melissa e hortelã (testemunha, 0\%) mostraram valores superiores de germinação e vigor quando comparado com as demais concentrações (25\%, 50\%, $75 \%$ e $100 \%)$, evidenciando o efeito alelopático de melissa e hortelã sobre o desenvolvimento de plântulas de tanchagem, determinado pelo comportamento germinativo, tanto da velocidade (vigor) como da percentagem final (Figuras 1, 2 e 3).

TABELA1. Equações e respectivos coeficientes de determinação ajustados para índice de velocidade de germinação de sementes de tanchagem submetidas a diferentes concentrações do extrato aquoso de melissa (IVGM), índice de velocidade de germinação de sementes de tanchagem submetidas a diferentes concentrações do extrato aquoso de hortelã (IVGH), porcentagem de germinação de sementes de tanchagem submetidas a diferentes concentrações do extrato aquoso de hortelã (PGH).

\begin{tabular}{c|c}
\hline Equação ajustada & Coeficiente de Determinação \\
\hline IVGM $=6,02-2,66 x^{* *}+0,33 x^{2 * *}$ & 0,61 \\
IVGH $=2,64-1,45 x^{\star *}+0,19 x^{2 * *}$ & 0,57 \\
$P G H=86,6-46,9 x^{* *}+6,28 x^{2 * *}$ & 0,60 \\
\hline
\end{tabular}

** - significativos pelo teste t a $1 \%$ de probabilidade.

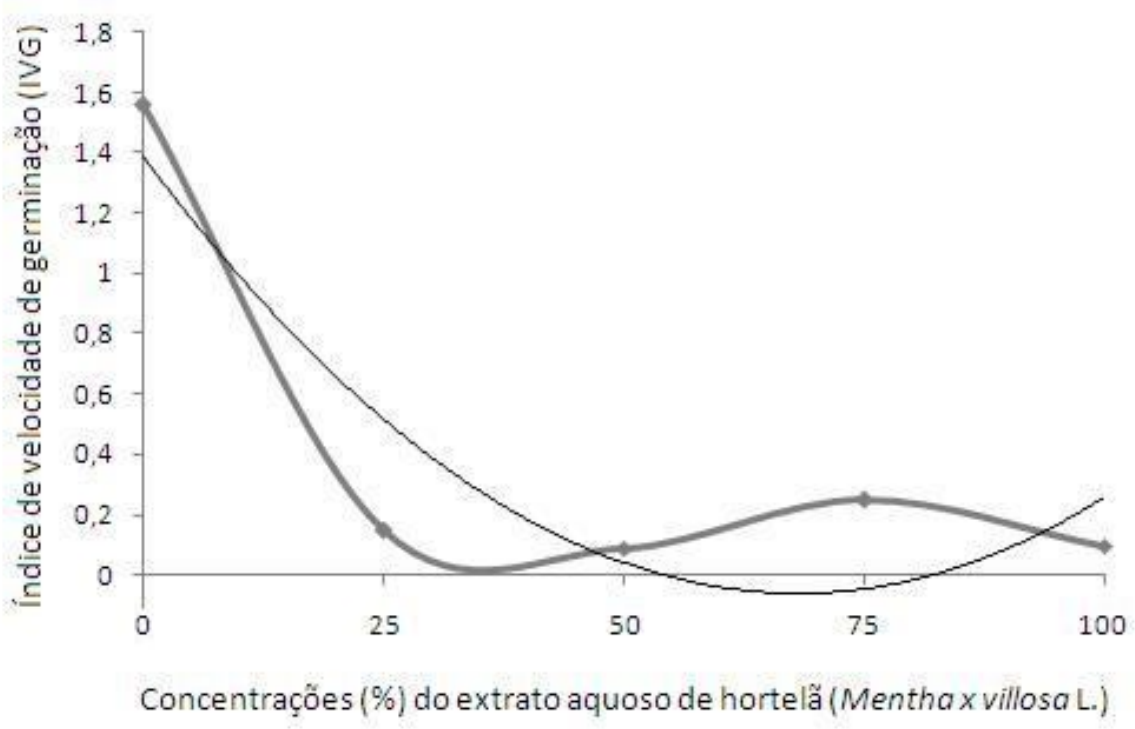

FIGURA 1. Índice de velocidade de germinação de sementes de tanchagem (Plantago major) submetidas a diferentes concentrações do extrato aquoso de hortelã (Mentha x villosa L.). Departamento de Fitotecnia, UFV, Viçosa, 2011. 


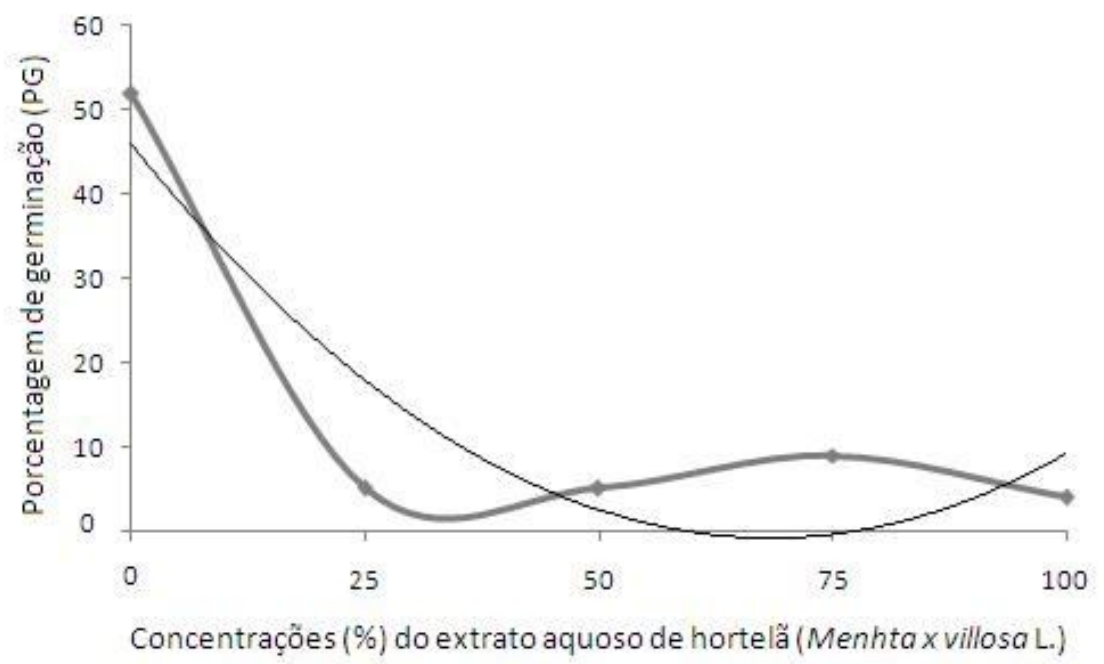

FIGURA 2. Porcentagem de germinação de sementes de tanchagem (Plantago major) submetidas a diferentes concentrações do extrato aquoso de hortelã (Mentha x villosa L.). Departamento de Fitotecnia, UFV, Viçosa, 2011.

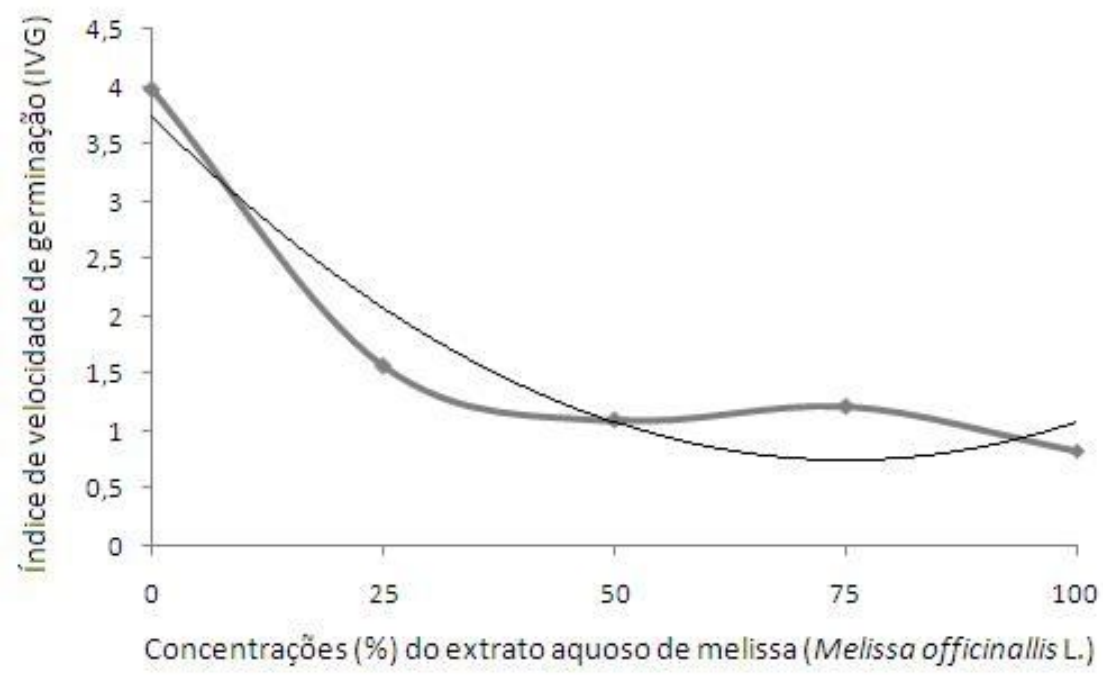

FIGURA 3. Índice de velocidade de germinação de sementes de tanchagem (Plantago major) submetidas a diferentes concentrações do extrato aquoso de melissa (Melissa officinallis L.). Departamento de Fitotecnia, UFV, Viçosa, 2011.

De acordo com Barreiro et al. (2005), as concentrações dos extratos aquosos de barbatimão (Stryphnodendron adstringes) prejudicaram com maior intensidade a velocidade de germinação das sementes no tratamento com extrato puro (100\%), seguido do tratamento com extrato diluído a $50 \%$, em relação ao controle. Esses resultados corroboram com os obtidos por Gorla \& Perez (1997), onde a velocidade de germinação de sementes de tomate também reduziu com o aumento da concentração dos extratos de folhas de Miconia albicans, Lantana câmara, Leucaena leucocephala e Drimys winteri.

Ferreira \& Borghetti (2002) afirmam que o efeito alelopático, muitas vezes, não se dá pela germinabilidade, mas sobre a velocidade de germinação, ou seja, sobre o vigor das sementes.
Pelos resultados obtidos, observa-se que os extratos aquosos hortelã, nas diferentes concentrações reduziram a germinação e o vigor das sementes. Extratos aquosos de melissa foram atuante somente inibindo o vigor das sementes de tanchagem. Assim, pode-se concluir que hortelã e melissa possuem efeito alelopático sobre a tanchagem, com isso, afetando o desenvolvimento inicial da planta.

\section{REFERÊNCIA}

BACCHI, O; LEITÃO FILHO, H.F; ARANHA, C. Plantas invasoras de culturas. Campinas: Instituto Campineiro de Ensino Agrícola, 906 p. 1984. 
BARREIRO, A.P; DELACHIAVE, M.E.A; SOUZA, F.S. Efeito alelopático de extratos de parte aérea de barbatimão [Stryphnodendron adstringens (Mart.) Coville] na germinação e desenvolvimento da plântula de pepino. Revista Brasileira de Plantas Medicinais, n.1, p. 4-8. 2005.

BONFIM, F.P.G; MAIA, J.T.L.S; BARBOSA, C.K.R; HONORIO, I.C.G; GUILHERME, D.O; MARTINS, E.R; COSTA, C.A. Influência do solo cultivado com hortelã (Mentha $X$ villosa) sobre a emergência de alface (Lactuca sativa). In: 47ํㅡㄴ CONGRESSO BRASILEIRO DE OLERICULTURA E IV SIMPÓSIO BRASILEIRO SOBRE CUCURBITÁCEAS. Anais...Porto Seguro. Horticultura Brasileira. Brasília : Associação Brasileira de Horticultura. v. 25. 2007.

BRASIL. Ministério da Agricultura e Reforma Agrária. Secretaria Nacional de Defesa Agropecuária. Departamento Nacional de Defesa Vegetal. Coordenação de Laboratório Vegetal. Regras para análise de sementes. Brasília, DF, 1992. 365p.

CORREA JÚNIOR, C; MING, L.C; SCHEFFER, M.C. Cultivo de plantas medicinais, condimentares e aromáticas. 2. ed. Jaboticabal: FUNEP. 162 p. 1994. FERREIRA, A.G; BORGHETTI, F. Germinação: Do básico ao aplicado. Porto Alegre: Editora Artmed, 324p. 2002. GORLA, C.M; PEREZ, S.C.J.G.A. Influência de extratos aquosos de folhas de Miconia albicans Triana, Lantana camara L., Leucaena leucocephala (Lam) de Wit e Drimys winteri Forst, na germinação e crescimento inicial de sementes de tomate e pepino. Revista Brasileira de Sementes, v.19, n.2, p. 261- 266. 1997.

JORGE, L.F; MARKMAN, B.E.O. Caracterização histológica e química (cromatografia em camada delgada) de Plantago tomentosa Lam. (Tanchagem). Revista Brasileira de Farmácia, v.75, n. 1, p. 10-12. 1994. KAWASLITY, A.A; GAMAL-EL-DIN, E; ABDALLA, M.F; SALEH, A.M. Flavonoides of Plantago species in Egipt. Biochemical Systematics and Ecology, v. 22, n. 7: 729733. 1994.

LORENZI, H; MATOS, F.J.A. Plantas medicinais no Brasil: nativas e exóticas cultivadas. Nova Odessa: Instituto Plantarum, 512p. 2002.

PIRES, N.M; PRATES, H.T; PEREIRA FILHO, I.A; OLIVEIRA JÚNIOR, R.S; FARIA, T.C.L. Atividade alelopática da leucena sobre espécies de plantas daninhas. Scientia Agricola v. 58, n.1, p. 61-65. 2001.

RODRIGUES, L.R.A; RODRIGUES, T.J.D; REIS, R.A. Alelopatia em plantas forrageiras. Jaboticabal: FUNEP, 68p. 1992.

SOARES, G.L.G. Inibição da germinação e do crescimento radicular de alface (cv. Grand Rapids) por extratos aquosos de cinco espécies de Gleicheniaceae. Floresta e Ambiente,v. 7, n.1, p.190-197. 2000. 